JOURNAL of

TOXICOLOGY and

ENVIRONMENTAL

HEALTH
Journal of Toxicology and Environmental Health, Part A

\title{
Children's Health and Indoor Air Quality in Primary Schools and Homes in Portugal-Study Design
}

Joana Madureira, Inês Paciência, Elisabete Ramos, Henrique Barros, Cristiana Pereira, João Paulo Teixeira \& Eduardo de Oliveira Fernandes

To cite this article: Joana Madureira, Inês Paciência, Elisabete Ramos, Henrique Barros, Cristiana Pereira, João Paulo Teixeira \& Eduardo de Oliveira Fernandes (2015) Children's Health and Indoor Air Quality in Primary Schools and Homes in Portugal-Study Design, Journal of Toxicology and Environmental Health, Part A, 78:13-14, 915-930, DOI: 10.1080/15287394.2015.1048926

To link to this article: http://dx.doi.org/10.1080/15287394.2015.1048926

Published online: 13 Jul 2015.

Submit your article to this journal

Џll Article views: 233

Q View related articles $\sqsubset$

View Crossmark data $־$

Citing articles: 3 View citing articles $ک 7$ 
Journal of Toxicology and Environmental Health, Part A, 78:915-930, 2015

Copyright $\odot$ Taylor \& Francis Group, LLC

ISSN: $1528-7394$ print / 1087-2620 online

DOI: $10.1080 / 15287394.2015 .1048926$

\title{
CHILDREN'S HEALTH AND INDOOR AIR QUALITY IN PRIMARY SCHOOLS AND HOMES IN PORTUGAL-STUDY DESIGN
}

\author{
Joana Madureira ${ }^{1}$, Inês Paciência ${ }^{1}$, Elisabete $\operatorname{Ramos}^{2,3}$, Henrique Barros ${ }^{2,3}$, Cristiana Pereira ${ }^{4}$, \\ João Paulo Teixeira ${ }^{4}$, Eduardo de Oliveira Fernandes ${ }^{1}$ \\ ${ }^{1}$ Institute of Mechanical Engineering and Industrial Management, Porto, Portugal \\ ${ }^{2}$ Public Health Institute, University of Porto, Porto, Portugal \\ ${ }^{3}$ Department of Clinical Epidemiology, Predictive Medicine and Public Health, University of Porto \\ Medical School, Porto, Portugal \\ ${ }^{4}$ National Institute of Health, Porto, Portugal National Institute of Health, Porto, Portugal
}

The main aim of the research project "On the Contribution of Schools to Children's Overall Indoor Air Exposure" is to study associations between adverse health effects, namely, allergy, asthma, and respiratory symptoms, and indoor air pollutants to which children are exposed to in primary schools and homes. Specifically, this investigation reports on the design of the study and methods used for data collection within the research project and discusses factors that need to be considered when designing such a study. Further, preliminary findings concerning descriptors of selected characteristics in schools and homes, the study population, and clinical examination are presented. The research project was designed in two phases. In the first phase, 20 public primary schools were selected and a detailed inspection and indoor air quality (IAQ) measurements including volatile organic compounds (VOC), aldehydes, particulate matter $\left(\mathrm{PM}_{2.5}, \mathrm{PM}_{10}\right)$, carbon dioxide $\left(\mathrm{CO}_{2}\right)$, carbon monoxide (CO), bacteria, fungi, temperature, and relative humidity were conducted. A questionnaire survey of 1600 children of ages 8-9 years was undertaken and a lung function test, exhaled nitric oxide (eNO), and tear film stability testing were performed. The questionnaire focused on children's health and on the environment in their school and homes. One thousand and ninety-nine questionnaires were returned. In the second phase, a subsample of 68 children was enrolled for further studies, including a walk-through inspection and checklist and an extensive set of IAQ measurements in their homes. The acquired data are relevant to assess children's environmental exposures and health status.

Children's environmental exposure history is a complex result of several factors, including exposure to air outdoors and mainly indoors in different indoor environments (AnnesiMaesano et al., 2013). In their earliest years, children remain mostly indoors and the home environment is the most dominant air exposure scenario. As children grow, they come into contact with a wider array of environments and related exposures. At this stage, the combined exposure to indoor air at home and in school may represent the major influence on child's health (Host et al., 2005; Kozyrskyj et al., 2009). The World Health Organization (WHO) assessed the contribution of a range of risk factors to the burden of disease and identified indoor air pollution as the eighth most important risk factor, responsible for $2.7 \%$ of the global burden of disease (WHO, 2010). Children are highly susceptible to indoor air pollution effects for a variety of reasons (Foos et al., 2008; WHO, 2010).

Uncertainty remains as a factor in the causative role of indoor air pollution in asthma

Address correspondence to Joana Madureira, Institute of Mechanical Engineering and Industrial Management, Rua Dr. Roberto Frias, 4200-465 Porto, Portugal. E-mail: jvm@fe.up.pt 
and respiratory allergies, but evidence suggests that several air pollutants may contribute to both asthma and allergies exacerbation and development (WHO, 2010; Vigotti et al., 2007; Oliveira Fernandes et al., 2008; Selgrade et al., 2008). Evaluating the risk of developing childhood asthma is one of the four priority issues identified by the European Community, under the European Union Environment and Health Action Plan (WHO, 2010). In addition, prevention of health effects resulting from poor indoor air quality (IAQ) is needed in all regions globally (WHO, 2010). Bearing this in mind, some studies have been conducted in schools to identify potential associations between exposure to indoor air and health (Franklin 2007; Hansel et al., 2008; Annesi-Maesano et al., 2013; Madureira et al., 2014). Indoor air pollution constitutes a complex case for risk assessment due to a wide number of aspects such as climate and outdoor air, building technologies and materials, the wide variety of pollutants and exposure levels, and manner of building utilization (Bluyssen et al., 1996). Moreover, methods employed in IAQ investigations ranged from (1) epidemiological approaches, in which questionnaires and health/comfort data were used in combination with or not clinical tests and/or collection of biomarker samples, to (2) field studies addressing chemical, physical and biological exposures in a small sample, and to (3) clinical/toxicological studies within controlled exposure conditions.

A few studies have been conducted in Portugal concerning IAQ in schools and adverse health effects in children (Fraga et al., 2008; Madureira et al., 2009, 2012, 2014; Pegas et al., 2011a, 2011b; Martins et al., 2012; Mendes et al., 2014), but none of these studies considered the combined exposure in schools and homes. In addition, the comparisons between studies are difficult due to different methodologies for IAQ measurements and, most commonly, lack of knowledge regarding the actual conditions of the different studies. Such knowledge is needed to improve indoor environmental conditions in homes and schools, the two settings that represent the majority of children's total exposure, in order to limit exposures that may induce or contribute to asthma, allergy, and other respiratory symptoms in children. Thus, the main aim of the research project entitled "On the Contribution of Schools to Children's Overall Indoor Air Exposure" was to study associations between adverse health effects, namely, allergy, asthma, and respiratory symptoms, and indoor air pollutants to which children are exposed to in schools and homes. Specifically, this investigation aimed to design and assess methods used for data collection within the research project and to describe factors that need to be considered when designing such a study.

\section{STUDY DESIGN AND METHODS}

\section{Content and Main Phases}

The study was conducted in Porto, the second largest city in Portugal, located in the north of the country at the seashore $\left(41^{\circ} \mathrm{N}, 8^{\circ} \mathrm{W}\right)$. A cross-sectional study including a large sample of schools and schoolchildren and a case-control study in a subsample of homes of asthmatic (case) and nonasthmatic children (control) were performed. Both investigations were conducted during the winter season (phase 1: between November 2011 and December 2012; and phase 2: between November 2012 and March 2013), as this period provides the worst-case scenario of exposure for the most critical indoor parameters.

\section{Ethical Issues}

The study was conducted according to the guidelines laid down in the Declaration of Helsinki and was approved by the Ethics Committee of the University of Porto (22/CEUP/2011). Written informed consent was obtained from parents/legal guardians of the children. 


\section{Selection of the Buildings, Indoor Spaces, and Recruitment}

Schools and Classrooms At the beginning of the study (2011/2012 academic year) about 40,000 children attended the 4669 public primary schools in Portugal; Porto municipality had 53 public primary schools with about 9680 children. Children's group sample size was estimated considering that the prevalence of childhood asthma in Portugal is 10\% (Falcão et al., 2008) and that exposure to poor indoor air leads to a twofold higher risk of having symptoms. Within these premises, a sample of 1600 children was established. Thus, assuming 20 children per room (DGEEC, 2014) and 4 classrooms per school, a sample size of 20 schools was evaluated. From the 53 public primary schools of Porto Municipality, 20 (38\%) schools with the highest number of students were selected. In each school, four classrooms of third and/or fourth grades (children aged 8-9 years) were selected among the classrooms with similar conditions. Preference was given to classrooms with high densities of occupation ( $\mathrm{m}^{2} /$ occupant) and full-week occupation time by the same class, and, if possible, on different floors.

Homes and Bedrooms Asthmatic and nonasthmatic children were identified among those who participated in the cross-sectional study. Asthmatic cases were selected on the basis of an affirmative response to one of the following questions in the health questionnaire: "Has your child ever had asthma diagnosed by a doctor?" and "In the past 12 months, has your child had wheezing or whistling in the chest?" Controls were selected among those children whose parents/legal guardians had answered "no" to both questions. In both groups, cases were excluded whenever homes had been recently rebuilt/refurbished $(<6 \mathrm{mo})$ or a change of residence had occurred since completing the questionnaire.

Based on the gathered data on children's health outcome obtained through the questionnaires, 68 homes among asthmatic and nonasthmatic children were included in the case-control study. The recruitment of the participants was performed in two steps. In the first step (March 2012), all parents who had participated up to then $(n=667)$ were asked for permission to allow air measurements in their homes. This invitation was sent by a letter describing the study in general and more specifically the environmental assessment. A prepaid and preaddressed return envelope was enclosed in the letter. Forty-one families agreed to participate (four homes of asthmatic children). Three weeks after receiving the parents' consent, research staff attempted to contact the parents by telephone. Despite their previous written consent, nine parents/legal guardians retracted their agreement to participate. Authorization was obtained to evaluate 32 homes: 4 from asthmatic children (cases) and 28 from nonasthmatic children (controls). In the second step, based on the questionnaires from the second-phase schools, random recruitment contacts were made by telephone in order to invite and schedule visits for home assessment. If the telephone was not answered, after several unsuccessful attempts the child/family was deemed as a nonresponder (passive refusal). Parents of 34 participants (out of 40) who fulfilled the criteria to be a case and 2 controls (out of 350) agreed to participate. The final sample participating in the case-control study comprised 68 children subdivided into two groups, 38 asthmatics and 30 nonasthmatics.

\section{Field Investigation in Buildings}

The field investigation included a walkthrough inspection by a trained researcher using a checklist and air monitoring equipment for the assessment of the chemical, physical, and comfort parameters and microbiological agents. In addition, all participants answered a self-reporting questionnaire and were subjected to a set of clinical tests and biomarkers.

Walk-Through Inspection and Checklist The checklist completed in schools and classrooms focused on the built environment and indoor spaces. The checklist observed detailed information regarding the building environment such as traffic and 
rural/urban surroundings, construction characteristics, ventilation system, and processes to maintain and operate the building and its activities, such as cleaning activities/schedule, renovation, and retrofitting activities. Further, a second form was completed for each classroom identifying all relevant information such as area, finishing materials, and conditions concerning floor, walls, and ceiling; windows; past occurrences and visible problems; heating and ventilation system; didactic materials, including paintings and glues and others; and maintenance routines and cleaning procedures. The type of classroom furniture and the presence of chalkboards, copiers, and plants were also noted, as well as information about the eventual use of environmental modifiers including air fresheners and insecticides.

With respect to homes and bedrooms, in addition to a walkthrough inspection, a specific checklist was used. The checklist focused on the built and indoor environment through characterization of building, systems, and rooms, such as operable or no windows, characteristics of the built environment, processes to maintain and operate the building, and its activities. Further, the parents were requested to complete a time-activity diary reporting number of occupants, their personal activities, which included smoking, cooking and cleaning activities, and ventilation habits. The families were also asked to maintain their regular routine during the environmental monitoring.

Environmental Monitoring In schools the air sampling (indoor and outdoor) encompassed a 5-day period (school week, from Monday morning until Friday afternoon); at homes it was considered a period of 7 days (from Saturday through Friday). These air samplings were not performed in parallel. At homes, the bedroom was chosen as the room where the child spends most of his or her time at home. Safe and childproof sampling locations were selected complying with ISO 16000-1 (2004). Classrooms samples were collected at breathing zone within the height of 1-1.5 $\mathrm{m}$ above the floor. Sampling locations were no closer than $1 \mathrm{~m}$ to any walls, door or active heating system. Further, the indoor sampling locations were selected as far away as possible from blackboards. At homes, indoor samples were collected from the rear of the bedroom complying also ISO 16000-1 (International Organization for Standardization [ISO], 2004). Outdoor samples were mounted in a shelter protecting from direct sunlight and precipitation at heights of $1-2 \mathrm{~m}$ above the ground and no closer than $1 \mathrm{~m}$ to any walls or buildings. All equipment used was calibrated once per year according to manufacturer specifications.

Volatile organic compounds (VOC) were collected using stainless-steel sampling tubes containing Tenax TA (60/80 mesh). The Tenax tubes were transferred to the lab and thermally desorbed (Dani STD 33.50), and samples were quantified using a nonpolar column by gas chromatography (Agilent Technologies $6890 \mathrm{~N}$ ) coupled to a mass spectrometry detector (Agilent Technologies 5973), according to ISO 16000, part 6 (ISO, 2011b). Total VOC (TVOC) concentration was quantified using the toluene response factor, and concentrations were calculated as the sum of VOC eluting between hexane and hexadecane (included), expressed as toluene. To control contamination during transport and sampling, a field blank was employed in every school and for every three homes. All samples were taken in duplicate to verify the reproducibility of measurements.

Aldehydes (formaldehyde and acetaldehyde) were sampled by Radiello passive devices (RAD 165, Sigma Aldrich), consisting of a cartridge filled with 2,4-dinitrophenylhydrazine $\quad(2,4-$ DNPH). By reaction with 2,4-DNPH, aldehydes yielded the corresponding 2,4dinitrophenyllhydrazones, which was desorbed in $2 \mathrm{ml}$ acetonitrile (Sigma-Aldrich) and manually stirred for $30 \mathrm{~min}$. Then the solution was passed through a a polyvinyl difluoride $0.45-\mathrm{mm}$ syringe filter $(13 \mathrm{~mm}$ syringe filter, Specanalítica) and determined using isocratic reverse-phase high-performance liquid chromatography (Agilent Technologies, 1220 Infinity LC) with an ultraviolet (UV) detector operated at $360 \mathrm{~nm}$ according to ISO 16000-4 (ISO, 2011a). Aldehydes were 
identified and quantified by comparison of their retention times and peak areas with those of standard solutions. Each cartridge was sealed after sampling and brought back to the lab, where it was stored in a refrigerator $\left(<4^{\circ} \mathrm{C}\right)$. As an internal quality control, duplicate samplings were collected in one school for each three schools, and in one bedroom per each three homes. Field blanks were collected and analyzed to assess possible contamination through the sample collection and analysis process. The limits of detection (LOD) were $0.075 \mu \mathrm{g} / \mathrm{m}^{3}$ for formaldehyde and 0.178 $\mu \mathrm{g} / \mathrm{m}^{3}$ for acetaldehyde.

Carbon monoxide (CO) concentrations were measured continuously using an IAQCALC monitor (model 7545, TSI, Inc.). The instrument includes an electrochemical sensor in a range from 0 to $500 \mathrm{ppm}$ (0 to $572.8 \mathrm{mg} / \mathrm{m}^{3}$ ) with accuracy of $\pm 3 \%$ of reading or $\pm 3 \mathrm{ppm}\left(3.4 \mathrm{mg} / \mathrm{m}^{3}\right)$. Measurements were conducted with a time step of $5 \mathrm{~min}$.

Two TSI DustTrak DRX photometers (model 8533; TSI, Inc.) were used to continuously monitor the particulate matter (PM) $\left(\mathrm{PM}_{2.5}\right.$ and $\mathrm{PM}_{10}$ ) concentration. Particles were measured with a laser photometer based on the light scattering. The measuring range of the equipment is 1 to $150 \times 10^{3} \mu \mathrm{g} / \mathrm{m}^{3}$ with accuracy of $\pm 0.1 \%$ of reading of $1 \mu \mathrm{g} / \mathrm{m}^{3}$ and the equipment operates with a flow rate of $3 \mathrm{~L} /$ min using a built-in diaphragm pump powered by an internal battery. The measurements were conducted at 1-min intervals for a $24-\mathrm{h}$ period in each indoor (classroom or bedroom) and outdoor location. As a consequence of the limited number of sampling units, indoor and outdoor PM could not be sampled in parallel.

Carbon dioxide $\left(\mathrm{CO}_{2}\right)$ concentrations were measured continuously using an IAQ-CALC monitor (model 7545, TSI, Inc.). The instrument includes an infrared nondispersive sensor in a range from 0 to 5000 ppm with accuracy of $\pm 3 \%$ of reading or $\pm 50 \mathrm{ppm}$. The same equipment was used for the measurements of temperature and relative humidity (IAQ-CALC monitor, model 7545, TSI, Inc.). The equipment includes a thermistor for measuring temperature in a range from 0 to $60^{\circ} \mathrm{C}$ with an accuracy of $\pm 0.6^{\circ} \mathrm{C}$, and a thin-film capacitive sensor for relative humidity (range of 5 to $95 \%$ relative humidity; accuracy $\pm 3.0 \%$ relative humidity). Carbon dioxide, temperature, and relative humidity measurements were conducted with a time step of $5 \mathrm{~min}$.

For microbiological agents, air samples were obtained using a single-stage microbiological air impactor (Airldeal, bioMérieux SA) according to the National Institute for Occupational Safety and Health (NIOSH) Method 0800 (NIOSH, 1998). This is a handheld, battery-operated instrument with a holder for a 90-mm-diameter nutrient agar plate and a sieve plate containing 220 holes. A fan draws air through the sieve plate, enabling airborne particles to impact on the agar plate, and air is exhausted through the side of the sampler. Tryptic soy agar (supplemented with $0.25 \%$ cycloheximide) and malt extract agar (supplemented with $1 \%$ of chloramphenicol) were used as culture media for bacteria and fungi, respectively. Air was drawn through the sampler at $100 \mathrm{~L} / \mathrm{min}$, and sequential duplicate air samples (duplicates of 100 and $250 \mathrm{~L}$ ) were collected indoors and outdoors (in one sampling point both in classrooms and in bedrooms). For each sampling day, agar media blanks for each culture media were taken into the field but not opened. After each sampling, the impactor was cleaned with cotton swabs wetted in isopropyl alcohol. After sampling, the agar media plates were sealed, marked, and transported to the lab in a thermal bag for incubation. To quantify bacterial and fungal concentrations, samples were incubated at $37 \pm 1{ }^{\circ} \mathrm{C}$ for $48 \pm 3 \mathrm{~h}$ and at $25 \pm 3{ }^{\circ} \mathrm{C}$ for $72 \pm 3$ h, respectively (EN 13098: European Standards, 2000). The bacteria and fungi colonies were then enumerated and concentrations were evaluated in colony-forming units per cubic meter of air $\left(\mathrm{CFU} / \mathrm{m}^{3}\right)$, taking into account a positive hole correlation factor to correct for the possibility that more than one particle containing a cultivable microorganism passes through the same hole (Andersen, 1958). The limit of quantification (LOQ) is established as $10 \mathrm{CFU}$ per plate, and maximal count is 1632 CFU per plate. Quantification 
limits associated to microbial plate count were established upon validation procedures: The minimum LOQ is the minimum count to obtain consistent duplicates, that is, reasonable accepted precision, following a Poison distribution (Hung et al., 2005), while the maximal LOQ (upper limit) is established by the positive hole correction provided by the manufacturer's instruction manual (bioMérieux, 2006).

\section{Health Assessment}

Health Questionnaire A paper-based questionnaire was completed by parents/legal guardians on a voluntary basis. The questionnaire was based on the standardized and validated Portuguese version (Rosado Pinto, 2011) of a questionnaire used in previous studies, namely, in the International Study of Asthma and Allergies in Childhood (ISAAC) (Asher et al., 1995). It included questions about respiratory/allergic health of the child; current symptoms/diagnosis (during the past $3 \mathrm{mo}$ ); and socioeconomic characteristics, building characteristics of the home, in particular the child's bedroom, and environmental tobacco smoke (ETS) exposure.

Clinical Tests and Biomarkers Clinical tests and biomarkers were performed at school during normal school hours by a team of experienced researchers following standardized procedures. All children for whom parental consent had been obtained were invited to measure weight, height, and lung function (obtained by spirometry tests). Exhaled nitric oxide (eNO) and tear film stability were performed in a subsample of five children from each classroom. These children were randomly selected from the participating children. Body weight was measured using a digital scale (Tanita: Tanita TBF-300, Tanita Corporation of America, Inc., Arlington Heights, IL; kg, to the nearest $0.1 \mathrm{~kg})$, and height was measured $(\mathrm{cm}$, to the nearest $0.1 \mathrm{~cm}$ ) using a portable stadiometer (SECA 214). Both were measured with the child upright and standing without shoes. Then the body mass index was calculated (weight $[\mathrm{kg}] / \mathrm{m}^{2}$ ).
Lung function was measured using a portable spirometer (ML3500, MicroLab) by a well-trained technician. All spirometry tests were performed according to American Thoracic Society (ATS)/European Respiratory Society (ERS) (ATS/ERS, 2005) guidelines. In brief, immediately following a full inhalation, the child seals his or her lips around the mouthpiece and blasts air out as rapidly as possible until the lungs are completely empty. Demonstration to children of the procedure and the maximal effort required was performed before starting, and the best of three technically acceptable tests was considered the final result. Values for forced vital capacity (FVC), forced expiratory volume in $1 \mathrm{~s}\left(\mathrm{FEV}_{1}\right)$, $\mathrm{FEV}_{1} / \mathrm{FVC}$ ratio, and forced expiratory flow $25-75 \%\left(\mathrm{FEF}_{25-75 \%}\right)$ were expressed as percent predicted value for statistical analysis.

The levels of eNO were measured according to the ATS/ERS guidelines (ATS/ERS, 2005) with the handheld device NIOX MINO system (Aerocrine, Stockholm, Sweden) with a detection limit of $5 \mathrm{ppb}$. The analyzer provides online continuous measurement of nitric oxide (NO). After children exhaled residual volume, they inserted the mouthpiece; subsequently they inhaled NO-free air from the apparatus to the total lung capacity and then exhaled for $10 \mathrm{~s}$ at a constant flow rate of $50 \mathrm{ml} / \mathrm{s}$. The endpoint of measurement occurred when a plateau for at least $2 \mathrm{~s}$ was observed. A visual feedback helped the children achieve the desired expiratory flow of $50 \mathrm{ml} / \mathrm{s}( \pm 10 \%)$.

Tear film stability was estimated by a standardized method, assessing self-reported breakup time (SBUT), recording the time (in seconds) the child could keep his or her eyes open without blinking, when watching a fixed point at the wall. This method, used previously (Wieslander et al., 1999), has a reliable correlation with the fluorescein method for detection of tear film BUT (Kjaergaard, 1992; Wyon, 1992). The child was sitting, looking at a fixed point on the wall at about $5 \mathrm{~m}$ (a flower painted with a felt pen). The child was instructed to blink on command, when a stopwatch is started, and to fix the point on the wall until the child felt the need to blink again. The time between blinks 
is recorded three times. The average of the two most concordant tests per children was used for the statistical analyses.

\section{Data Management and Statistical Analysis}

All data, from the checklist as well as from the questionnaire, were transferred using an "optical mark reading" device with dedicated scanner software in order to streamline data input processes and reduce input error. A descriptive analysis was performed to characterize the buildings and indoor spaces investigated as well as participants.

Symptoms and diseases were grouped by typology: asthma-like, rhinitis-like, skin diseases, and other respiratory diseases apart from cold (Table 1S).

Table $2 \mathrm{~S}$ shows the list of recent ( $<3$ months) symptoms by organ in children assessed through the question "During the past three months, has your child had any of the following symptoms?" The possible replies were (1) no, never; (2) yes, sometimes (1-3 times/month); (3) yes, often (1-4 times/week); and (4) yes, daily; however, data analysis considered only two outputs: "yes" and "no."

The Shapiro-Wilk test was used for normality testing. The distribution of all indoor air parameters was skewed. Data were analyzed using SPSS Statistics version 19.

\section{RESULTS AND DISCUSSION}

\section{Characterization of the School Buildings and Classrooms}

The main characteristics of the 20 investigated school buildings are presented in Table 1. Smoking was not allowed by law in any indoor space of any school building. In total, $13(65 \%)$ schools were situated close to a heavily trafficked road, 5 (25\%) schools were close to a car park, and $2(10 \%)$ schools were close to gasoline dispensing facilities. Table 1 also shows selected characteristics of the investigated classrooms. The most common floor covering was synthetic smooth floor tiles (PVC/vinyl, linoleum; 65.8\%). Not a single case of wall-to-wall carpeting was present. Each classroom was equipped with standard school furniture, predominantly made of plywood. It was found that approximately 30\% of classrooms had a closet or shelves with gouaches and inks and glues for arts classes. None of the classrooms had any mechanical ventilation system, and opening windows was the only means to ventilate. During the winter season, windows were usually closed due to outdoor weather conditions, outdoor noise, and/or heating systems being turned on. All classrooms had heating equipment, with the most frequent type being electrical radiators. All classrooms were cleaned daily with a broom or, less commonly, a vacuum cleaner at the end of the classes (afternoon).

\section{Environmental Monitoring in Classrooms}

Carbon monoxide, $\mathrm{PM}_{2.5}, \mathrm{PM}_{10}, \mathrm{CO}_{2}$, temperature, and relative humidity levels were calculated from data collected during teaching periods to ensure that the sample was representative of the total exposure time; data for TVOC, formaldehyde, and acetaldehyde, measured in parallel and continuously over $24 \mathrm{~h}$ for 5 consecutive days, were noted for a school week. A summary of indoor measurements taken in the 73 classrooms is presented in Table 2. The median TVOC concentration was $140.3 \mu \mathrm{g} / \mathrm{m}^{3}$ (P25-P75 = 85.5-198.4 $\left.\mu \mathrm{g} / \mathrm{m}^{3}\right)$. The median values of VOC, formaldehyde, and $\mathrm{CO}$ levels were lower than guideline values established by the WHO (2010) and the EU-INDEX project (Kotzias et al., 2005).

Regarding PM, the indoor median concentration of $\mathrm{PM}_{2.5}$ and $\mathrm{PM}_{10}$ in all classrooms exceeded the $25-\mu \mathrm{g} / \mathrm{m}^{3}$ and $50-\mu \mathrm{g} / \mathrm{m}^{3}$ guideline levels suggested by $\mathrm{WHO}$ air quality guidelines for a sampling period of $24 \mathrm{~h}$ (Table 2). Among the 73 classrooms surveyed, $86 \%$ of the classrooms $(n=63)$ had median $\mathrm{CO}_{2}$ concentrations exceeding $1000 \mathrm{ppm}$. Higher values were measured in classrooms with higher occupant density. 
TABLE 1. Characteristics of the Investigated School Buildings and Classrooms

\begin{tabular}{|c|c|c|}
\hline Building characteristics & $n(\%)$ & \\
\hline \multicolumn{3}{|l|}{ Location } \\
\hline Industrial area & 0 & \\
\hline Mixed industrial/residential area & $1(5)$ & \\
\hline Commercial area & 0 & \\
\hline Mixed commercial/residential area & $1(5)$ & \\
\hline City center, densely packed housing & $4(20)$ & \\
\hline Town, with no or small gardens & $14(70)$ & \\
\hline Suburban, with larger gardens & 0 & \\
\hline Village in a rural area & 0 & \\
\hline Rural area with no or few other hones nearby & 0 & \\
\hline \multicolumn{3}{|l|}{ Construction period } \\
\hline Before 1980 & $16(84.2)$ & \\
\hline 1980-1989 & $2(10.5)$ & \\
\hline 1990-1999 & $1(5.3)$ & \\
\hline 2000 or after & 0 & \\
\hline \multicolumn{3}{|l|}{ Building refurbished } \\
\hline Yes & $20(100)$ & \\
\hline No & 0 & \\
\hline Classrooms characteristic & $n(\%)$ & Mean \pm SD \\
\hline \multicolumn{3}{|l|}{ Surface area and occupancy } \\
\hline Floor area $\left(\mathrm{m}^{2}\right)$ & - & $51 \pm 6$ \\
\hline Volume $\left(\mathrm{m}^{3}\right)$ & - & $171 \pm 23$ \\
\hline Occupants per classroom (number) & - & $21 \pm 3$ \\
\hline Density of occupation ( $\mathrm{m}^{2} /$ occupant) & - & $2.4 \pm 0.4$ \\
\hline \multicolumn{3}{|l|}{ Type of floor } \\
\hline Synthetic smooth (PVC/vinyl, linoleum) & $48(65.8)$ & - \\
\hline Wooden & $25(34.2)$ & - \\
\hline \multicolumn{3}{|l|}{ Type of floor } \\
\hline Synthetic smooth (PVC/vinyl, linoleum) & $48(65.8)$ & - \\
\hline Wooden & $25(34.2)$ & - \\
\hline \multicolumn{3}{|l|}{ Wall surface } \\
\hline Water-based paint & $73(100.0)$ & - \\
\hline \multicolumn{3}{|l|}{ Ceiling surface } \\
\hline Wooden & $7(9.6)$ & - \\
\hline Painted & $66(90.4)$ & - \\
\hline \multicolumn{3}{|l|}{ Type of board } \\
\hline Blackboard and chalk & $24(32.9)$ & - \\
\hline Whiteboard with pen & $49(67.1)$ & - \\
\hline \multicolumn{3}{|l|}{ Interactive board } \\
\hline No & $26(35.6)$ & - \\
\hline Yes & $47(64.4)$ & - \\
\hline \multicolumn{3}{|l|}{ Heating system } \\
\hline Hot water radiators/convectors & $9(12.3)$ & - \\
\hline Electrical radiators/convectors & $60(82.2)$ & - \\
\hline Heating floor & $4(5.5)$ & - \\
\hline \multicolumn{3}{|l|}{ Damp stains } \\
\hline No & 59 (80.8) & - \\
\hline Yes & $14(19.2)$ & - \\
\hline \multicolumn{3}{|l|}{ Visible mold } \\
\hline No & $53(72.6)$ & - \\
\hline Yes & $20(27.4)$ & - \\
\hline
\end{tabular}

Note. SD: standard deviation.

With respect to microbiological agents, classrooms had a median bacterial concentration higher than $1000 \mathrm{CFU} / \mathrm{m}^{3}$, and in some cases indoor levels were higher than $3000 \mathrm{CFU} / \mathrm{m}^{3}$. Indoor fungi concentrations ranged from 61 to $1322 \mathrm{CFU} / \mathrm{m}^{3}$ 
TABLE 2. Distribution of Indoor Chemical, Physical, and Comfort Parameters and Microbiological Agents in Classrooms $(n=$ 73 Classrooms)

\begin{tabular}{|c|c|c|c|c|c|}
\hline & \multicolumn{5}{|c|}{ Percentiles } \\
\hline & $\overline{1 \%}$ & $25 \%$ & $50 \%$ & $75 \%$ & $99 \%$ \\
\hline \multicolumn{6}{|l|}{ Chemical } \\
\hline TVOC, $\mu \mathrm{g} / \mathrm{m}^{3}$ & 8.88 & 85.5 & 140.3 & 198.4 & 792.6 \\
\hline Formaldehyde, $\mu \mathrm{g} / \mathrm{m}^{3}$ & 8.24 & 13.8 & 17.5 & 23.1 & 39.0 \\
\hline Acetaldehyde, $\mu \mathrm{g} / \mathrm{m}^{3}$ & 1.92 & 4.96 & 7.65 & 10.4 & 64.6 \\
\hline $\mathrm{CO}, \mathrm{mg} / \mathrm{m}^{3}$ & 0 & 0.07 & 0.38 & 0.68 & 1.70 \\
\hline \multicolumn{6}{|l|}{ Physical and comfort } \\
\hline $\mathrm{PM}_{2.5}, \mu \mathrm{g} / \mathrm{m}^{3}$ & 42 & 67 & 82 & 106 & 242 \\
\hline $\mathrm{PM}_{10}, \mu \mathrm{g} / \mathrm{m}^{3}$ & 58 & 109 & 127 & 167 & 290 \\
\hline $\mathrm{CO}_{2}, \mathrm{ppm}$ & 829 & 1195 & 1469 & 2104 & 3111 \\
\hline Temperature, ${ }^{\circ} \mathrm{C}$ & 14.3 & 19.2 & 20.8 & 21.7 & 24.6 \\
\hline Relative humidity, \% & 34 & 50 & 54 & 65 & 72 \\
\hline \multicolumn{6}{|l|}{ Microbiological } \\
\hline Bacteria, CFU $/ \mathrm{m}^{3}$ & 10 & 1784 & 3224 & 5430 & 8372 \\
\hline Fungi, $\mathrm{CFU} / \mathrm{m}^{3}$ & 61 & 169 & 240 & 400 & 1089 \\
\hline
\end{tabular}

Note. TVOC: total volatile organic compounds.

(median $\left.=240 \mathrm{CFU} / \mathrm{m}^{3}\right)$ (Table 2). Descriptive data on outdoor measurements, as well on ondoor/outdoor $(\mathrm{I} / \mathrm{O})$ ratios, are given in Table $3 \mathrm{~S}$ and Table $4 \mathrm{~S}$, respectively.

\section{Participant Characterization}

In total, 1639 children were invited to participate in the survey. Although 1134 parents consented to participation of their child in at least one of the components of the study, namely, the health questionnaire and/or the clinical health examination (participation rate of $69.2 \%$ ), the parents' questionnaire study resulted in collection of data for only 1099 children out of 1639. One hundred and eighty-one (11\%) parents refused to participate and 324 $(19.8 \%)$ did not return the signed consent form and parents' questionnaire and were therefore considered refusals. Table 3 shows an overview of the participants and their homes.

\section{Health Outcomes Prevalence}

In lifetime, ever wheezing (30.7\%) was the most frequent symptoms (Table 4). Regarding the past year, the most frequently reported symptoms were dry cough at nighttime $(32.2 \%)$, nasal allergy (25.4\%), and eye irritation (12.9\%), followed closely by wheezing $(11.1 \%)$. The prevalence of diagnosed asthma and diagnosed nasal allergy was $9.7 \%$ and $12.5 \%$, respectively. A summary of the recent symptoms $(<3 \mathrm{mo})$ analysis is shown in Table 5. Blocked nose $(56.5 \%)$ was the condition most reported, followed by runny nose $(46.9 \%)$, sore throat $(41.8 \%)$, headaches $(36.6 \%)$, and irritating cough (33.5\%).

In this survey the prevalence of wheeze ever and wheeze in the preceding $12 \mathrm{mo}$ is higher than that found in the national ISAAC evaluation (Porto ISAAC-Phase III, children 6-7 years old; http://isaac.auckland.ac. $\mathrm{nz}$ ). Regarding the EPITeen cohort study, carried out in Porto and including adolescents 13 years of age, the prevalence of the symptoms just described was lower than values obtained in the current study (wheeze ever $=18.3 \%$ and wheeze in the last year $=9.3 \%$ ) (Falcão et al., 2008). In addition, EPITeen results demonstrated a higher frequency of asthma diagnosis $(11.9 \%)$ than that obtained in the present study $(9.7 \%)$. In this survey, doctor-diagnosed nasal allergy was reported in $12.5 \%$, but a higher percentage of children had runny nose symptoms (46.9\%) and blocked nose symptoms (56.5\%). The frequency of ever nasal allergy in the current study was lower than the prevalence of nose symptoms ever noted in the Porto ISAACPhase III data $(16.5 \%$ vs. $26.1 \%)$. The values 
TABLE 3. Characteristics of the Participants and Their Homes $(n=1099)$

\begin{tabular}{|c|c|}
\hline Characteristic & $n^{*}(\%)$ \\
\hline \multicolumn{2}{|l|}{ Gender } \\
\hline Girls & 570 (51.9) \\
\hline Boys & $529(48.1)$ \\
\hline Age (years) ${ }^{* \dagger}$ & $8.60(0.73)$ \\
\hline Body mass index $\left(\mathrm{BMI}, \mathrm{kg} / \mathrm{m}^{2}\right)^{* \dagger}$ & $18.3(3.22)$ \\
\hline \multicolumn{2}{|l|}{ Doctor-diagnosed asthma $^{+}$} \\
\hline No & $967(90.3)$ \\
\hline Yes & $104(9.7)$ \\
\hline \multicolumn{2}{|l|}{ Family history of any allergic disorders } \\
\hline No & $608(55.3)$ \\
\hline Yes & $491(44.7)$ \\
\hline \multicolumn{2}{|l|}{ Number of siblings ${ }^{\dagger}$} \\
\hline None & $191(18.9)$ \\
\hline 1 & $498(49.4)$ \\
\hline 2 or more & $320(31.7)$ \\
\hline \multicolumn{2}{|l|}{ Mothers' education level $^{+}$} \\
\hline $0-6$ years & $222(21.2)$ \\
\hline $7-9$ years & $208(19.9)$ \\
\hline 10-12 years & $270(25.8)$ \\
\hline$\geq 13$ years & $346(33.1)$ \\
\hline \multicolumn{2}{|l|}{ Fathers' education level $^{+}$} \\
\hline $0-6$ years & $227(22.9)$ \\
\hline $7-9$ years & $242(24.4)$ \\
\hline $10-12$ years & $240(24.2)$ \\
\hline$\geq 13$ years & $283(28.5)$ \\
\hline \multicolumn{2}{|l|}{ Location of the home from traffic } \\
\hline Far away from traffic & $235(22.6)$ \\
\hline With low (reasonable) traffic & $447(43.0)$ \\
\hline Near to traffic & $357(34.4)$ \\
\hline \multicolumn{2}{|l|}{ Type of home ${ }^{\dagger}$} \\
\hline Single-family house & $85(8.1)$ \\
\hline Semidetached house & $107(10.2)$ \\
\hline Apartment & $786(74.9)$ \\
\hline Other (including farm) & $72(6.9)$ \\
\hline \multicolumn{2}{|l|}{ Size of the home $\left(\mathrm{m}^{2}\right)$} \\
\hline$<50$ & $55(9.6)$ \\
\hline $50-100$ & $235(41.2)$ \\
\hline $101-150$ & $152(26.6)$ \\
\hline$>150$ & $129(22.6)$ \\
\hline Building age (years)*† & $28.7(30.5)$ \\
\hline
\end{tabular}

${ }^{\dagger}$ Denominator for each variable may vary due to missing data.

*Mean (standard deviation).

are similar for prevalence of nasal allergy in the past 12 mo reported in our study (25.4\%) and frequency of nose symptoms in the last year according to Porto ISAAC results (22.1\%).

\section{Clinical Health Examination}

From the 1099 children considered in this analysis, 842 children (435 girls) underwent pulmonary function tests, 359 children (183 girls) performed the eNO test, and
363 children (186 girls) performed the SBUT (Table 6). Most parameters of pulmonary function were significantly higher in girls. Eighty-six (24\%) of the schoolchildren $(17.5 \%$ of girls) displayed an eNO value over $20 \mathrm{ppb}$, with a greater percentage of values above $35 \mathrm{ppb}$ (10.9\% of children) in boys (13.6\%). The global mean (SD) of eNO was 18.5 (17.4) ppb. On average, children keep their eyes open without blinking for 26.9 (45) s.

\section{Environmental Monitoring at Homes}

Table 7 provides descriptive data for indoor measured parameters among case and control homes. The median concentration of TVOC was $97.4 \mathrm{\mu g} / \mathrm{m}^{3}$ with a maximum of 793.6 $\mu \mathrm{g} / \mathrm{m}^{3}$ measured in a case home; in control homes the median TVOC levels were $125 \mu \mathrm{g} / \mathrm{m}^{3}$. Aldehydes were detected in all samples. Levels of formaldehyde were below the current indoor exposure guidelines of 100 $\mu \mathrm{g} / \mathrm{m}^{3}$ (WHO, 2010). No significant difference was observed between case and control homes.

Data on $\mathrm{PM}_{2.5}$ and $\mathrm{PM}_{10}$ were missing in 26 case homes and 12 control homes due to technical problems in the measurement equipment during the field campaign. Median concentrations of $\mathrm{PM}_{2.5}$ and $\mathrm{PM}_{10}$ were lower in the homes of children with asthma $\left(54 \mu \mathrm{g} / \mathrm{m}^{3}\right.$ vs. $67 \mu \mathrm{g} / \mathrm{m}^{3}$ for $\mathrm{PM}_{2.5} ; 56 \mu \mathrm{g} / \mathrm{m}^{3}$ vs. 71 $\mu \mathrm{g} / \mathrm{m}^{3}$ for $\left.\mathrm{PM}_{10}\right)$. Further, approximately $61 \%$ of the measured bedrooms showed median $\mathrm{CO}_{2}$ concentration above 1000 ppm; approximately $4 \%$ of the rooms had an average $\mathrm{CO}_{2}$ concentration exceeding 2000 ppm, although none of the rooms exceeded $3000 \mathrm{ppm}$. These numbers might be higher if one considered that $59.3 \%$ of case family dwellings and $62.5 \%$ of control family homes did not comply with the 1000 ppm reference value.

Bacteria concentrations in the homes of asthmatic children varied widely from 98 to $6528 \mathrm{CFU} / \mathrm{m}^{3}$ (median $=774 \mathrm{CFU} / \mathrm{m}^{3}$ ), and in control homes it varied from 188 to $6528 \mathrm{CFU} / \mathrm{m}^{3}\left(\right.$ median $\left.=652 \mathrm{CFU} / \mathrm{m}^{3}\right)$; however, there were no significant differences. 
TABLE 4. Prevalence of Ever, Past Month, and Past Year Symptoms/Diseases in Children $(n=1099)$

\begin{tabular}{|c|c|c|c|c|c|c|c|}
\hline \multirow[b]{2}{*}{ Symptom/disease } & \multicolumn{2}{|l|}{ Girls } & \multicolumn{2}{|l|}{ Boys } & \multirow[b]{2}{*}{$p$ Value } & \multicolumn{2}{|l|}{ Total } \\
\hline & $n$ & $\%$ & $n$ & $\%$ & & $n$ & $\%$ \\
\hline \multicolumn{8}{|l|}{ Asthma-like } \\
\hline Ever wheeze ${ }^{\dagger}$ & 136 & 24.8 & 188 & 37.1 & $<.001$ & 324 & 30.7 \\
\hline Wheeze $(<12 \mathrm{mo})$ & 43 & 7.8 & 74 & 14.6 & .001 & 117 & 11.1 \\
\hline Wheeze $(<30 \mathrm{~d})$ & 21 & 3.8 & 31 & 6.1 & .089 & 52 & 4.9 \\
\hline Doctor-diagnosed asthma $^{\dagger}$ & 36 & 6.5 & 68 & 13.2 & $<.001$ & 104 & 9.7 \\
\hline Asthma in school ${ }^{\dagger}$ & 12 & 2.2 & 15 & 2.9 & .432 & 27 & 2.5 \\
\hline \multicolumn{8}{|l|}{ Rhinitis-like } \\
\hline Ever runny/blocked nose ${ }^{\dagger *}$ & 157 & 28.4 & 162 & 31.3 & .293 & 319 & 29.8 \\
\hline Nasal allergy $(<12 \mathrm{mo})^{\dagger *}$ & 133 & 24.1 & 139 & 26.9 & .287 & 272 & 25.4 \\
\hline Eye irritation $(<12 \mathrm{mo})^{\dagger *}$ & 67 & 12.1 & 71 & 13.7 & .430 & 138 & 12.9 \\
\hline Ever nasal allergy & 66 & 11.9 & 109 & 21.5 & $<.001$ & 175 & 16.5 \\
\hline Doctor-diagnosed nasal allergy & 51 & 9.2 & 82 & 16.1 & .001 & 133 & 12.5 \\
\hline \multicolumn{8}{|l|}{ Skin diseases } \\
\hline Ever itchy rash (for $6 \mathrm{mo})^{+}$ & 100 & 18.2 & 99 & 19.5 & .597 & 199 & 18.8 \\
\hline Ever eczema $^{\dagger}$ & 103 & 19.3 & 95 & 19.0 & .894 & 198 & 19.1 \\
\hline \multicolumn{8}{|c|}{ Other respiratory diseases apart from cold } \\
\hline Dry cough at night $(<12 \mathrm{mo})^{\dagger}$ & 177 & 32.2 & 164 & 32.3 & .972 & 341 & 32.2 \\
\hline Cough episodes & 75 & 13.9 & 55 & 10.8 & .130 & 130 & 12.4 \\
\hline Phlegm episodes & 60 & 11.3 & 52 & 10.5 & .692 & 112 & 10.9 \\
\hline
\end{tabular}

${ }^{\dagger}$ Denominator for each variable may vary due to missing data.

* Not occurring due to cold.

TABLE 5. Prevalence of Recent Symptoms ( $<3$ mo) Among Children $(n=1099)$

\begin{tabular}{|c|c|c|c|c|c|c|c|}
\hline \multirow[b]{2}{*}{ Symptom } & \multicolumn{2}{|l|}{ Girls } & \multicolumn{2}{|l|}{ Boys } & \multirow[b]{2}{*}{$p$ Value } & \multicolumn{2}{|l|}{ Total } \\
\hline & $n$ & $\%$ & $n$ & $\%$ & & $n$ & $\%$ \\
\hline \multicolumn{8}{|l|}{ Skin } \\
\hline 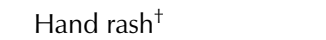 & 46 & 8.6 & 42 & 8.8 & .902 & 88 & 8.7 \\
\hline Face rash ${ }^{\dagger}$ & 37 & 6.9 & 31 & 6.5 & .779 & 68 & 6.7 \\
\hline Eczema & 41 & 7.9 & 35 & 7.5 & .799 & 76 & 7.7 \\
\hline \multicolumn{8}{|l|}{ Eye } \\
\hline Eye irritation & 85 & 16.4 & 95 & 19.8 & .430 & 180 & 18.0 \\
\hline Swollen eye ${ }^{\dagger}$ & 39 & 7.6 & 44 & 9.2 & .353 & 83 & 8.4 \\
\hline \multicolumn{8}{|l|}{ Nose } \\
\hline Runny nose ${ }^{\dagger}$ & 254 & 48.4 & 216 & 45.3 & .327 & 470 & 46.9 \\
\hline Blocked nose & 301 & 57.0 & 272 & 56.0 & .739 & 573 & 56.5 \\
\hline \multicolumn{8}{|l|}{ Lower airways } \\
\hline Dry throat $^{\dagger}$ & 124 & 23.9 & 113 & 24.0 & .971 & 237 & 23.9 \\
\hline Sore throat ${ }^{\dagger}$ & 241 & 45.7 & 181 & 37.6 & .009 & 422 & 41.8 \\
\hline Irritating cough & 171 & 32.9 & 166 & 34.2 & .653 & 337 & 33.5 \\
\hline Shortness of breath ${ }^{+}$ & 69 & 13.4 & 86 & 18.2 & .039 & 155 & 15.7 \\
\hline \multicolumn{8}{|l|}{ Systemic } \\
\hline Headache $^{\dagger}$ & 205 & 38.6 & 167 & 34.4 & .168 & 372 & 36.6 \\
\hline Nausea $^{+}$ & 71 & 13.9 & 51 & 10.8 & .139 & 122 & 12.4 \\
\hline $\begin{array}{l}\text { Symptom(s) improve on } \\
\text { returning home }\end{array}$ & 54 & 15.0 & 50 & 15.2 & .941 & 104 & 15.1 \\
\hline
\end{tabular}

${ }^{\dagger}$ Denominator for each variable may vary due to missing data.

Concerning fungi levels, higher indoor levels were observed in the control group (case group vs. control group: $170 \mathrm{CFU} / \mathrm{m}^{3}$ vs. $301 \mathrm{CFU} / \mathrm{m}^{3}$.).
Descriptive data on outdoor measurements are given in Table 5S. The number of outdoor measurements was less than indoors, mainly due to weather conditions and to lack 
TABLE 6. Description of the Clinical Tests and Biomarkers

\begin{tabular}{|c|c|c|c|c|c|c|c|}
\hline \multirow{2}{*}{$\begin{array}{l}\text { Clinical tests and } \\
\text { biomarkers }\end{array}$} & \multicolumn{2}{|l|}{ Girls } & \multicolumn{2}{|l|}{ Boys } & \multirow[b]{2}{*}{$p$ Value } & \multicolumn{2}{|l|}{ Total } \\
\hline & Mean & SD & Mean & SD & & Mean & SD \\
\hline FVC & 102.3 & 11.2 & 103.0 & 10.6 & .186 & 102.8 & 20.6 \\
\hline $\mathrm{FEV}_{1}$ & 107.4 & 11.4 & 105.6 & 10.9 & .021 & 106.6 & 11.2 \\
\hline $\mathrm{FEV}_{1} / \mathrm{FVC}$ & 105.2 & 5.50 & 102.7 & 5.27 & $<.05$ & 104.0 & 5.54 \\
\hline $\mathrm{FEF}_{25-75 \%}$ & 112.6 & 21.0 & 107.0 & 19.8 & $<.05$ & 109.8 & 20.6 \\
\hline $\mathrm{eNO}$ & 16.4 & 14.4 & 20.7 & 19.8 & .019 & 18.5 & 17.4 \\
\hline SBUT & 23.9 & 24.1 & 30.1 & 59.4 & .627 & 26.9 & 45.0 \\
\hline
\end{tabular}

Note. FVC: forced vital capacity; $\mathrm{FEV}_{1}$ : forced expiratory volume in $1 \mathrm{~s} ; \mathrm{FEF}_{25-75 \%}$ : forced expiratory flow 25-75\%; eNO: exhaled nitric oxide; SBUT: self-reported breakup time; SD: standard deviation.

of appropriate location. In general, outdoor concentrations were lower than indoor levels. In the present study, the $\mathrm{I} / \mathrm{O}$ ratios obtained in particular for formaldehyde, acetaldehyde, and bacteria in both groups indicated a notable contribution of internal sources (Table 6S).

\section{Strengths and Limitations}

Of particular note as strengths are the questionnaire-based survey; all clinical tests and biomarkers being conducted by the same research team; and inclusion of school children aged 8-9 years, as well as environmental monitoring at both homes and schools, to more fully understand child's total indoor air exposure. The current study is relevant to complement existing information and help future investigations, as it provides a useful indication in terms of factors and steps that might be considered when designing such a study. The current study included a large sample size regarding the number of classrooms, as well as detailed health and clinical information in particular when compared with earlier studies carried out in Portugal (Fraga et al., 2008; Madureira et al., 2009, 2012, 2014; Pegas et al., 2011a, 2011b; Martins et al., 2012; Mendes et al., 2014). In addition, potential risk factors were considered and identified using a common procedure that provides sufficient statistical power to evaluate their impact. Moreover, detailed health data on a large number of children (participation rate of about $70 \%$ ) were collected in the questionnaire study, which allows for a relatively unbiased estimate of the prevalence of asthma and allergic and respiratory symptoms. However, a potential limitation is the selection bias, that is, when parents of allergic children might be more willing to respond to questionnaires focusing on asthma/allergy compared to parents of nonallergic children (Bornehag et al., 2012). Further, parents of children with allergies may also answer in systematically different ways compared to parents of children without allergy (reporting bias). Minimizing all these potential biases and achieving higher response rates are known to improve data quality in questionnaire studies (Morton et al., 2006). Although the participation rate of $69.2 \%$ was reasonably high, the possibility of selection bias still needs to be considered. It is noteworthy that the selection bias is likely to be minimal, taking also into account that the frequency of asthma obtained in the present study is in agreement with findings of previous studies (Falcão et al., 2008; Fraga et al., 2008). However, there is a general trend of declining response rates in many parts of the world, leading to a higher risk of bias affecting the validity of results (Koshy and Brabin, 2012). One possible reason for lower response rates might be that the number of studies (both scientifically based and those more commercially focused) increased markedly recently, which might make people less willing to answer surveys (Barclay et al., 2002; Morton et al., 2006).

\section{CONCLUSIONS}

This investigation outlines the study design and methods that might be followed by future 


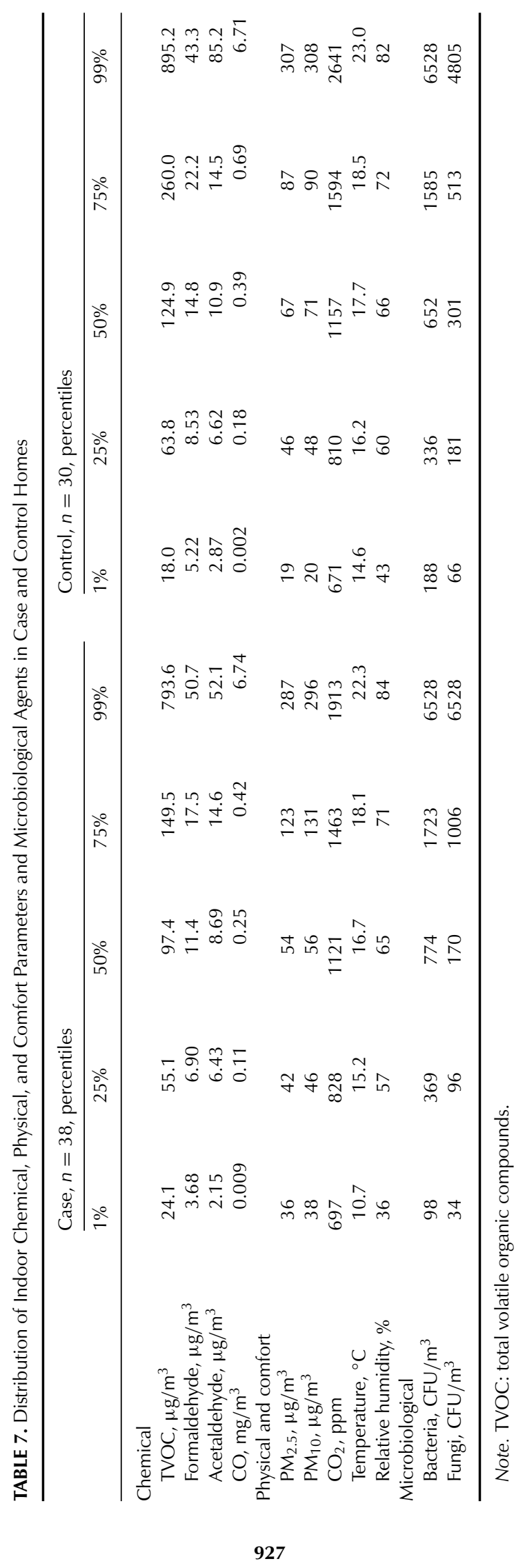


researchers conducting large-scale field studies of potential relationships between indoor air pollutants and selected health endpoints. The acquired data are relevant to children's environmental exposures and health status. The preliminary findings describe study participants (including clinical examination) and characteristics of their schools and homes. The next step in ongoing analyses is to examine (1) potential associations between study population, (2) characteristics of their homes and schools, and (3) health endpoints taking into account all potential confounders, as reported by parents and obtained from clinical examinations. Such knowledge is needed to improve indoor environmental conditions in homes and schools, the two settings that represent the majority of children's total exposure, and, consequently to limit exposures that may induce or contribute to asthma, allergy, and other respiratory symptoms in children.

\section{SUPPLEMENTAL DATA}

Supplemental data for this article can be accessed at http://dx.doi.org/10.1080/ 15287394.2015.1048926

\section{FUNDING}

This work was supported by Fundação para Ciência e Tecnologia through the ARIA project (PTDC/DTP-SAP/1522/2012).

\section{REFERENCES}

American Thoracic Society and European Respiratory Society. 2005. ATS/ERS recommendations for standardized procedures for the online and offline measurement of exhaled lower respiratory nitric oxide and nasal nitric oxide, 2005. Am. J. Respir. Crit. Care 171: 912-930.

Andersen, A. A. 1958. New sampler for the collection, sizing, and enumeration of viable airborne particles. J. Bacteriol. 76: 471-784. Annesi-Maesano, I., N. Baiz, S. Banerjee, P. Rudnai, S. Rive, and Group The Sinphonie.
2013. Indoor air quality and sources in schools and related health effects. J. Toxicol. Environ. Health B 16: 491-550.

Asher, M. I., U. Keil, H. R. Anderson, R. Beasley, J. Crane, F. Martinez, E. A. Mitchell, N. Pearce, B. Sibbald, A. W. Stewart, D. Strachan, S. K. Weiland, and H. C. Williams. 1995. International Study of Asthma and Allergies in Childhood (ISAAC)—Rationale and methods. Eur. Respir. J. 8: 483-491.

Barclay, S., C. Todd, I. Finlay, G. Grande, and P. Wyatt. 2002. Not another questionnaire! Maximizing the response rate, predicting non-response and assessing non-response bias in postal questionnaire studies of GPs. Family Pract. 19: 105-111.

bioMérieux. 2006. air IDEAL 3P Manual de Utilização Part 2. http://www.biomerieuxusa.com/industry/air-ideal

Bluyssen, P. M., E. De Oliveira Fernandes, L. Groes, G. Clausen, P. O. Fanger, O. Valbjørn, C. A. Bernhard, and C. A. Roulet. 1996. European Indoor Air Quality Audit Project in 87556 Office Buildings. http://onlinelibrary.wiley.com/doi/ 10.1111/j.1600-0668.1996.00002.x/epdf

Bornehag, C.G., S. Moniruzzaman, M. Larsson, C.B. Lindstrom, M. Hasselgren, A. Bodin, L.B. von Kobyletzkic, F. Carlstedt, F. Lundin, E. Nanberg, B.A. Jonsson, T. Sigsgaard, and S. Janson. 2012. The SELMA study: A birth cohort study in Sweden following more than 2000 mother-child pairs. Paediatr. Perinat. Epidemiol. 26: 456-467.

Direção-Geral de Estatísticas da Educação e Ciência. Educação em números, Portugal 2012. 2014. https://educar.files.wordpress. com/2014/09/cneturmas.jpg

European Standards. 2000. CSN EN 13098Workplace atmosphere-Guidelines for measurement of airborne micro-organisms and endotoxin. Available at: http://www. en-standard.eu/csn-en-13098-workplace atmosphere-guidelines-for-measurement-of airborne-micro-organisms-and-endotoxin/.

Falcão, H., E. Ramos, A. Marques, and H. Barros. 2008. Prevalence of asthma and rhinitis in 13 year old adolescents in Porto, Portugal. Rev. Port. Pneumol. 14: 747-768. 
Foos, B., M. Marty, J. Schwartz, W. Bennett, J. Moya, A. M. Jarabek, and A. G. Salmon. 2008. Focusing on children's inhalation dosimetry and health effects for risk assessment: an introduction. J. Toxicol. Environ. Health A 71: 149-165.

Fraga, S., E. Ramos, A. Martins, M. J. Samudio, G. Silva, J. Guedes, E. Oliveira Fernandes, and H. Barros. 2008. Indoor air quality and respiratory symptoms in Porto schools. Rev. Port. Pneumol. 14: 487-507.

Franklin, P. J. 2007. Indoor air quality and respiratory health of children. Paediatr. Respir. Rev. 8: 281-286.

Hansel, N. N., P. N. Breysse, M. C. McCormack, E. C. Matsui, J. Curtin-Brosnan, D. L. Williams, J. L. Moore, J. L. Cuhran, and G. B. Diette. 2008. A longitudinal study of indoor nitrogen dioxide levels and respiratory symptoms in inner-city children with asthma. Environ. Health Perspect. 116: 1428-1432.

Host, A., S. Halken, and L. K. Poulsen. 2005. The influence of environmental factors on the development of allergy. Ugeskr. Laeger. 167: 613-617.

Hung, L.-L., J. D. Miller, and H. K. Dillon. 2005. Field guide for the determination of biological contaminants in environmental samples. American Industrial Hygiene Association, USA.

International Organization for Standardization. 2004. ISO 16000-1:2004. Indoor airPart 1: General aspects of sampling strategy. International Organization for Standardization. Available at http://www.iso. org/iso/home/standards.htm

International Organization for Standardization. 2011a. ISO 16000-4:2011. Determination of formaldehyde-Diffusive sampling method. International Organization for Standardization. Available at http://www.iso. org/iso/home/standards.htm

International Organization for Standardization. 2011b. International Standard ISO 16000-6 Indoor air-Part 6 Determination of volatile organic compounds in indoor and test chamber air by active sampling on Tenax TA sorbent, thermal desorption and gas chromatography using MS/FID. International
Organization for Standardization. Available at Available at http://www.iso.org/iso/home/ standards.htm

Kjaergaard, S. 1992. Assessment of eye irritation in humans. Ann. Acad. Sci. 641: 187-198.

Koshy, G., and B. J. Brabin. 2012. Parental compliance-An emerging problem in Liverpool community child 4 health surveys 1991-2006. BMC Med. Res. Methodol. 12: 53.

Kotzias, D., K. Koistinen, S. Kephalopoulos, C. Schlitt, P. Carrer, M. Maroni, M. Jantunen, C. Cochet, S. Kirchner, T. Lindvall, J. McLaughlin, L. Molhave, E. Oliveira Fernandes, and B. Seifert. 2005. The INDEX project. Critical appraisal of the setting and implementation of indoor exposure limits in the EU. Final report. EUR 21590 EN. European Comission, Directorate General, Joint Research Centre. http://ec.europa. eu/health/ph_projects/2002/pollution/fp_ pollution_2002_frep_02.pdf

Kozyrskyj, A. L., K. T. HayGlass, A. J. Sandford, P. D. Pare, M. Chan-Yeung, and A. B. Becker. 2009. A novel study design to investigate the early-life origins of asthma in children (SAGE study). Allergy 64: 1185-1193.

Madureira, J., M. C. M. Alvim-Ferraz, S. Rodrigues, C. Goncalves, M. C. Azevedo, E. Pinto, and O. Mayan. 2009. Indoor air quality in schools and health symptoms among Portuguese teachers. Hum. Ecol. Risk Assess. 15: 159-169.

Madureira, J., I. Paciencia, and E. Oliveira Fernandes. 2012. Levels and indoor-outdoor relationships of size-specific particulate matter in naturally ventilated Portuguese schools. J. Toxicol. Environ. Health A 75: 1423-1436.

Madureira, J., C. Pereira, I. Paciencia, J. P. Teixeira, and E. de Oliveira Fernandes. 2014. Identification and levels of airborne fungi in Portuguese primary schools. J. Toxicol. Environ. Health A 77: 816-826.

Martins, P. C., J. Valente, A. L. Papoila, I. Caires, J. Araujo-Martins, P. Mata, M. Lopes, S. Torres, J. Rosado-Pinto, C. Borrego, I. AnnesiMaesano, and N. Neuparth. 2012. Airways 
changes related to air pollution exposure in wheezing children. Eur. Respir. J. 39: 246-253.

Mendes, A., D. Aelenei, A. L. Papoila, P. Carreiro-Martins, L. Aguiar, C. Pereira, P. Neves, S. Azevedo, M. Cano, C. Proenca, J. Viegas, S. Silva, D. Mendes, N. Neuparth, and J. P. Teixeira. 2014. Environmental and ventilation assessment in Child Day Care Centers in Porto: The ENVIRH Project. J. Toxicol. Environ. Health A 77: 931-943.

Morton, L. M., J. Cahill, and P. Hartge. 2006. Reporting participation in epidemiologic studies: A survey of practice. Am. J. Epidemiol. 163: 197-203.

National Institute for Occupational Safety and Health. 1998. NIOSH manual of analytical methods. NIOSH. http://www.cdc.gov/niosh/ docs/2003-154/pdfs/0800.pdf

Oliveira Fernandes, E., H. Gustafsson, O. Seppänen, D. Crump, and G. Ventura Silva. 2008. WP3 Final report on characterization of spaces and sources. EnVIE Project. Brussels, Belgium: European Commission 6th Framework Programme of Research.

Pegas, P. N., C. A. Alves, M. G. Evtyugina, T. Nunes, M. Cerqueira, M. Franchi, C. A. Pio, S. M. Almeida, and M. C. Freitas. 2011a. Indoor air quality in elementary schools of Lisbon in spring. Environ. Geochem. Health 33: 455-468.

Pegas, P. N., C. A. Alves, M. G. Scotto, M. G. Evtyugina, C. A. Pio, and M. C. Freitas. 2011b. Risk factors and prevalence of asthma and rhinitis among primary school children in Lisbon Rev. Port. Pneumol. 17: 109-116.

Rosado Pinto, J. 2011. ISAAC (International Study of Asthma and Allergies in Childhood) 20 anos em Portugal. Acta Pediatr. Port. 42: S26-S48.

Selgrade, M. K., C. G. Plopper, M. I. Gilmour, R. B. Conolly, and B. S. P. Foos. 2008. Assessing the health effects and risks associated with children's inhalation exposuresAsthma and allergy. J. Toxicol. Environ. Health A 71: 196-207.

Vigotti, M. A., F. Chiaverini, P. Biagiola, and G. Rossi. 2007. Urban air pollution and emergency visits for respiratory complaints in Pisa, Italy. J. Toxicol. Environ. Health A 70: 266-269.

Wieslander, G., D. Norbäck, K. Nordstrom, R. Walinder, and P. Venge. 1999. Nasal and ocular symptoms, tear film stability and biomarkers in nasal lavage, in relation to building-dampness and building design in hospitals. Int. Arch. Occup. Environ. Health 72: 451-461.

World Health Organization. 2010. WHO guidelines for indoor air quality: Selected pollutants. Copenhagen, Denmark: World Health Organization Regional Office for Europe.

Wyon, D. P. 1992. Sick buildings and the experimental approach. Environ. Technol. 13: 313-322. 